\title{
A constituição de uma novidade organizacional no Sul do Brasil: avanços e limites da participação da agricultura familiar
}

\author{
Advances and limits of the counter-trends: social arenas of an \\ organizational novelty in the South of Brazil
}

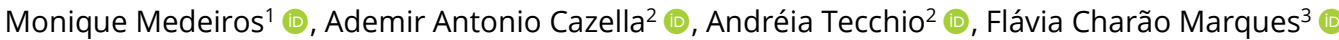 \\ ${ }^{1}$ Instituto Amazônico de Agriculturas Familiares, Programa de Pós-graduação em Agriculturas Amazônicas, Universidade \\ Federal do Pará (UFPA), Belém (PA), Brasil. E-mail: mmedeiros@ymail.com \\ ${ }^{2}$ Centro de Ciências Agrárias, Programa de Pós-graduação em Agroecossistemas, Universidade Federal de Santa Catarina \\ (UFSC), Florianópolis (SC), Brasil. E-mails: ademir.cazella@ufsc.br; deiatecchio@yahoo.com.br \\ ${ }^{3}$ Faculdade de Agronomia, Programa de Pós-graduação em Desenvolvimento Rural, Universidade Federal do Rio Grande do \\ Sul (UFRGS), Porto Alegre (RS), Brasil. E-mail: flavia.marques@ufrgs.br
}

Como citar: Medeiros, M., Cazella, A. A., Tecchio, A., \& Marques, F. C. (2020). A constituição de uma novidade organizacional no Sul do Brasil: avanços e limites da participação da agricultura familiar. Revista de Economia e Sociologia Rural, 58(3), e209211. https://doi.org/10.1590/1806-9479.2020.209211

\begin{abstract}
Resumo: As consequências negativas da "modernização" da agricultura têm induzido agricultores familiares, pesquisadores e mediadores sociais a construir ações de desenvolvimento rural que desviam do modelo hegemônico. Neste cenário, as "novidades" ou melhorias nos rearranjos de relações entre sociedade e tecnologia estão ocorrendo constantemente, não desprovidas de limitações. Este artigo discute as potencialidades e limites de processos de construção de uma novidade organizacional no litoral norte do Rio Grande do Sul, Brasil, com foco na participação de grupos de agricultores familiares. A investigação contemplou pesquisas documentais, participação observante e entrevistas semiestruturadas com agricultores familiares e mediadores sociais atuantes na região, realizadas entre meados de 2013 e o primeiro trimestre de 2016. Os resultados alcançados evidenciam que a consolidação da novidade organizacional assegura a reprodução socioeconômica de grupos de agricultores familiares, resgata costumes, fortalece vínculos sociais e reconecta esses agricultores à natureza. Entretanto, ainda que esse novo e desviante processo esteja propiciando transformações significativas na região, a apropriação de novos procedimentos sociotécnicos por apenas alguns grupos sociais faz com que outros, em especial aqueles constituídos por agricultores familiares vulneráveis socioeconomicamente, não participem das ações.
\end{abstract}

Palavras-chave: produção de novidade, reprodução socioeconômica, apropriação de discursos.

\begin{abstract}
The negative consequences of the agriculture modernization have induced family farmers, researchers and social mediators to construct rural development actions that deviate from the hegemonic model. In this scenario, the "novelties", or improvements in the rearrangements of relations between society and technology, are occurring constantly, not devoid of limitations. This paper aims to discuss the potentialities and limits of the processes of construction of an organizational novelty in the North Coast of Rio Grande do Sul, Brazil, focusing on the participation of groups of family farmers. The research included documentary research, observational participation and semi-structured interviews with family farmers and social mediators working in the region between mid-2013 and the first quarter of 2016. The results show that the consolidation of organizational novelty ensures the socioeconomic reproduction of groups of family farmers, rescues customs, strengthens social ties and reconnects these farmers to nature. However, although this new and deviant process is causing significant transformations in the region, the appropriation of new sociotechnical procedures by only a few social groups means that others, especially those composed of socioeconomically vulnerable family farmers, do not participate in the actions.
\end{abstract}

Keywords: novelty production, socioeconomic reproduction, speeches appropriation. 


\section{Introdução}

A desconexão da agricultura como prática sociocultural, fruto do processo de "modernização" da agricultura iniciado nos anos 1960, tem sido acompanhada de distintas ações de resistência por parte de diferentes categorias sociais de agricultores familiares. Ao invés de vivenciarem de forma passiva a desintegração dos seus modos de vida, esses agricultores transformaram o novo código de comunicação e de racionalidade que lhes foi imposto. Conforme suas necessidades e interesses, inter-relacionaram materialidades associadas à modernidade e à tradição (Arce \& Long, 2000; Lamarche, 1993).

No litoral norte do Rio Grande do Sul, por exemplo, um conjunto de agricultores, aliados a pesquisadores, extensionistas rurais e consumidores empreende iniciativas que implicam em reavaliações e reinvenções não somente de formas de produção agrícola, como também de novos projetos de desenvolvimento rural. Esses atores sociais constroem iniciativas inovadoras a partir da desconstrução de determinadas tecnologias para, então, efetuar uma combinação seletiva com elementos locais, que caracterizam cada modo de praticar agricultura (Long \& Van der Ploeg, 1994). Nesses processos é possível verificar o papel preponderante da família como estrutura fundamental de organização da reprodução social e da formulação de estratégias de transmissão do patrimônio material e cultural, bem como da unidade agrícola (Carneiro, 1999).

No local de estudo, a exemplo do que ocorreu na maior parte da região Sul do País, a "modernização" da agricultura se materializou por meio da difusão de pacotes tecnológicos, o que induziu os agricultores à adoção de cultivos específicos até então inexistentes na região (Cotrim et al., 2007). De forma pioneira, o cultivo de tabaco promovido por indústrias fumageiras remonta à década de 1950, tornando-se a principal alternativa para "modernizar" a agricultura da região. A cadeia produtiva de fumo integrou parcela significativa de agricultores do litoral norte do Rio Grande do Sul (Ação Nascente Maquiné, 2000; Gerhardt, 2002). Em paralelo, o uso de insumos sintéticos difundiu-se, em grande parte, com incentivos do governo estadual, que implantou na região um centro da Fundação Estadual de Pesquisa Agropecuária e escritórios municipais com profissionais da extensão rural da Associação Rio-grandense de Empreendimentos de Assistência Técnica e Extensão Rural/Associação Sulina de Crédito e Assistência Rural (Emater/Ascar - RS) (Medeiros, 2017).

Os efeitos desse processo marcam a realidade atual do litoral norte do Rio Grande do Sul. Uma forte especialização da agricultura está presente nas áreas de várzeas dos vales e nas planícies, praticada por agricultores com maior disponibilidade de áreas planas, que detêm uma melhor situação econômica. A maioria dos agricultores, no entanto, continua a cultivar nas encostas sem o uso intensivo de tecnologias, resultando em rendimentos inferiores quando comparados aos das áreas de várzea (Cotrim et al., 2007). Como parte considerável da paisagem local é constituída por remanescentes de florestas de Mata Atlântica, a partir do início da década de 1990 a fiscalização ambiental foi intensificada e as restrições legais de uso do solo e da vegetação geraram dificuldades principalmente para os agricultores das áreas de encostas.

Os agricultores familiares usuários dessas áreas empreenderam adaptações e reinvenções tecnológicas. Como resultado desse processo, a região se caracteriza na atualidade por um mosaico cultural e produtivo, com o predomínio de uma agricultura familiar voltada à produção de alimentos em sistemas diversificados, com destaque para a denominada agricultura de base ecológica. Trata-se de uma agricultura que desvia e contraria o modelo de agricultura convencional, o qual faz uso intenso de agroquímicos e depende de recursos naturais não renováveis. As práticas da agricultura de base ecológica têm como foco o equilíbrio entre os diversos fatores presentes no trabalho com a agricultura, a exemplo do bem-estar animal, não geração desperdícios (reaproveitando ao máximo o material que sobra das atividades) e participação em relações coletivas com o propósito de melhorar a qualidade de vida para as gerações atuais e futuras (Caporal \& Costabeber, 2004).

Os agricultores familiares implicados com esse tipo de agricultura constroem formas de cooperação que se caracterizam como uma "novidade", pois promovem um conjunto de melhorias e rearranjos nas relações sociais e de trabalho (Van der Ploeg et al., 2004). Entretanto, ainda que essa novidade valorize especificidades socioambientais e culturais e 
impulsione a reprodução socioeconômica de grupos de agricultores familiares, sua emergência não é desprovida de disputas de poder e de articulações entre distintas agências sociais ${ }^{1}$. Essas disputas estão atreladas a processos de diferenciação social, nos quais apenas alguns indivíduos, dotados de determinados recursos, atuam de modo a intervir em contextos específicos. Nesse sentido, este artigo tem por objetivo investigar as potencialidades e limites dos processos de construção de uma novidade organizacional no litoral norte do Rio Grande do Sul, Brasil, com foco na participação de distintos segmentos de agricultores familiares.

Trata-se de um estudo essencialmente qualitativo baseado em informações obtidas por meio de pesquisa documental e entrevistas semiestruturadas junto a mediadores sociais e agricultores familiares, além de participação observante. Entre agosto de 2013 e abril de 2016 foi possível acompanhar 26 mediadores sociais e 38 famílias de agricultores em suas atividades cotidianas nas feiras livres, nos encontros e reuniões, nas atividades nas lavouras e em suas relações com pesquisadores e gestores públicos ${ }^{2}$. Foram entrevistados 12 agricultores envolvidos com as organizações da agricultura familiar em construção na região de estudo e 26 agricultores não pertencentes a essas organizações, dentre os quais seis quilombolas e duas lideranças indígenas ${ }^{3}$, com o propósito de compreender as razões do distanciamento entre distintos grupos sociais. Além desses atores sociais, foram entrevistados 16 mediadores sociais atuantes no local, sendo 12 vinculados ao serviço público de extensão rural, quatro a Organizações Não Governamentais (ONG), dos quais dois são, também, pesquisadores universitários, e dez cooperativas de agricultores familiares, dentre os quais sete são agricultores.

O número de entrevistados foi determinado pela saturação amostral, definida pela repetição de informações fornecidas pelos distintos grupos de atores: agricultores participantes de organizações sociais, agricultores não participantes dessas organizações e mediadores sociais. A inclusão de novos participantes na investigação foi finalizada no momento em que as informações obtidas por meio das entrevistas indicaram a possibilidade de compreensão em profundidade do fenômeno estudado (Fraser \& Gondim, 2004). No que se refere aos representantes dos quilombolas e indígenas envolvidos na pesquisa, verificou-se que esses atores possuem especificidades socioculturais que explicam seu distanciamento das iniciativas organizacionais em construção na região.

As entrevistas semiestruturadas combinaram perguntas abertas e fechadas em roteiros pré-determinados. Assim, esses procedimentos metodológicos trouxeram acréscimos importantes à participação observante, pois captaram valores dos indivíduos e grupos presentes nos discursos e nos múltiplos atos do cotidiano, e possibilitaram identificar discrepâncias entre discursos e práticas realizados pelos atores sociais envolvidos com a problemática. Após sua realização e transcrição, as entrevistas foram úteis na investigação dos aspectos afetivos e valorativos dos informantes.

Com o intuito de analisar a transcendência de repertórios culturais particulares e a maneira que estes interagem e se interpenetram de acordo com determinada situação, a análise crítica do discurso complementou o quadro teórico-metodológico da pesquisa.

\footnotetext{
${ }^{1}$ Um dos primeiros autores a tratar sobre essa noção foi o sociólogo inglês Anthony Giddens (1989), para quem a agência não se refere às intenções que as pessoas têm para realizar determinadas coisas, mas, sobretudo, à sua capacidade de colocar essas coisas em prática. A agência depende da habilidade do indivíduo de gerar mudanças em relação a um estado de coisas ou curso de eventos preexistentes, o que implica que todos os agentes, mesmo aqueles que se encontram em posições de subordinação, se apropriam de um determinado tipo de poder e podem exercer influências.

${ }^{2}$ Tais atividades foram desenvolvidas pela primeira autora durante o curso de seu doutorado realizado junto ao Programa de Pós-Graduação em Agroecossistemas da Universidade Federal de Santa Catarina.

${ }^{3}$ No que se refere a comunidades quilombolas constituídas por descendentes de escravos, no município de Três Forquilhas, se encontra a comunidade quilombola Morro do Chapéu, da qual participam 40 famílias, e, em Terra de Areia, das comunidades Boa Vista e Zâmbia, com 10 e 5 famílias, respectivamente. No que concerne aos indígenas, no litoral norte do Rio Grande do Sul se encontram duas Reservas Indígenas (RI) e três Terras Indígenas Tradicionalmente Ocupadas. Em Torres situa-se a RI Campo Bonito, na qual 70 indígenas ocupam uma área de 94,83 ha e, em Osório, a RI Estrada do Mar, com uma área de 45 ha, onde habitam 50 indígenas. Entre Maquiné, Caraá e estendendo-se até o município de Riozinho (localizado fora da delimitação apresentada do litoral norte do Rio Grande do Sul), localiza-se a Terra Indígena (TI) Guarani Barra do Ouro, com 2.268,60 ha partilhados entre 20 indígenas. Abrangendo os municípios de Caraá e Maquiné, a TI de Varzinha conta com uma população de 78 indivíduos em uma extensão de 776,28 ha.
} 
Compreendendo-se por discurso um jogo de significados inseridos nas metáforas, representações, imagens, narrativas e, principalmente, na forma de prática social, modo de ação sobre o mundo e a sociedade, buscou-se, através dessa técnica, evidenciar uma versão particular de "verdade" acerca de objetos, pessoas, eventos e das relações construídas entre eles (Fairclought, 2001; Long, 2007).

A Figura 1 abaixo apresenta a localização da região de estudo, bem como os municípios onde se deram as principais ações da pesquisa empírica.

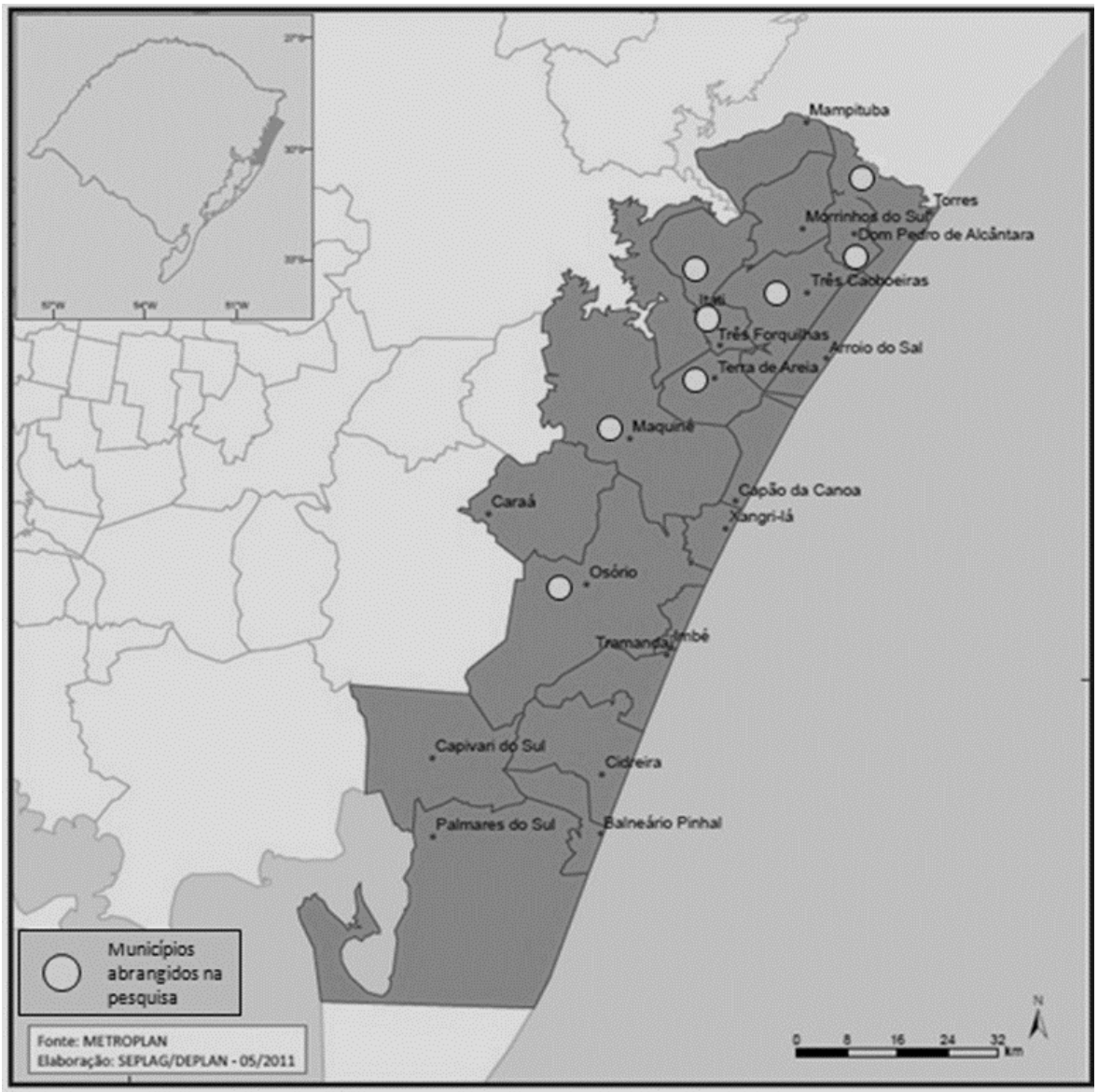

Figura 1. Localização da região do litoral norte do Rio Grande do Sul e municípios de origem dos agricultores familiares e mediadores sociais envolvidos na pesquisa. Adaptada de Fundação Estadual de Planejamento Metropolitano e Regional (2014).

Além desta introdução, quatro partes compõem a estrutura principal do artigo. Na primeira, a perspectiva teórica de produção de novidades é apresentada. Na segunda, as particularidades das formas de cooperação desencadeadas no recorte empírico são caracterizadas como uma novidade em consolidação. A terceira parte problematiza as disputas e apropriações de discursos que ocorrem nas arenas sociais que delineiam a construção e consolidação dessa novidade. A quarta parte apresenta as considerações finais, com ênfase às potencialidades dessas iniciativas e às suas limitações, em especial no que se refere à sua abrangência e consequências desencadeadas pela atual conjuntura político-econômica, que intensifica o contexto de exclusão da novidade analisada do público em situação de pobreza.

\section{As relações entre sociedade e tecnologia: "novidades" em debate}

A noção de produção de novidades (novelty production) foi originalmente difundida com a publicação de uma coletânea organizada por Van der Ploeg et al. (2004). No Brasil, diversos trabalhos mobilizaram a produção de novidades como instrumento analítico de pesquisas voltadas à sociologia rural. Dentre estes, destacam-se os estudos de doutorado de Marques 
(2009), Mello (2009), Gazolla (2012), Oliveira (2014), Nicola (2015) e Medeiros (2017). As distintas pesquisas empíricas realizadas abrangem problemáticas como o uso de plantas medicinais no Rio Grande do Sul, consolidação de organizações rurais no oeste de Santa Catarina, norte e litoral norte do Rio Grande do Sul e mudanças sociotécnicas na pecuária familiar na região centro-sul desse mesmo estado. Tais investigações têm avançado sobretudo no que se refere ao impulso de estratégias e políticas públicas voltadas ao fortalecimento da agricultura familiar e de projetos de desenvolvimento rural que desviam do modelo hegemônico.

Vale mencionar que duas razões principais explicam a formulação e o desenvolvimento progressivo da noção de produção de novidades. A primeira refere-se ao fato de o paradigma da "modernização" da agricultura ter formulado um "modelo" de inovações e de desenvolvimento tecnológico externalista, padronizado, globalizado e linear. Esse modelo provocou a desconexão entre a tecnologia e as práticas endógenas de agricultores. A segunda razão é o entendimento da necessidade de aprofundar o tratamento teórico dos temas da inovação e tecnologia (Wiskerke \& Van der Ploeg, 2004).

As primeiras concepções acerca do papel das tecnologias no desenvolvimento das sociedades foram formuladas já em 1776 por Adam Smith (Smith, 1996). Posteriormente, em 1867, Karl Marx, apesar de não apresentar uma teoria específica sobre o tema da inovação, considerada pelo autor um fator indissociável do desenvolvimento capitalista, associa a ideia de "progresso técnico" à extração de mais-valia ${ }^{4}$ (Marx, 2006). Para Marx, a evolução histórica do capitalismo faria com que o progresso técnico se ampliasse, ocasionando a substituição de parte da força de trabalho, sobretudo nas indústrias, pelas máquinas (Gazolla, 2012).

Alguns anos mais tarde, Schumpeter (1985) criou conceitos fundamentais ao debate sobre o papel das inovações no desenvolvimento econômico. Segundo esse autor, as inovações seriam definidas pela realização de novas combinações de recursos, as quais poderiam se referir à introdução de um novo bem, de uma nova tecnologia de produção, abertura de um novo mercado, conquista de uma nova fonte de matéria-prima ou de bens manufaturados e uma nova organização industrial. Essas inovações foram denominadas de empreendimentos e o agente econômico que operacionaliza as novas combinações de empresário. Sob seu ponto de vista, os empresários buscam as inovações em função da concorrência e do monopólio dos mercados como forma de proteção e garantia de lucros no sistema capitalista.

Nelson \& Winter (1977) complementaram a perspectiva schumpeteriana de inovação, evidenciando o seu caráter evolucionário. Segundo eles, os avanços tecnológicos do passado são cumulativos e as inovações, desenvolvidas em períodos temporais específicos, resultam da evolução de conhecimentos, das habilidades dos indivíduos e das rotinas das organizações econômicas. As rotinas são explicadas por Nelson \& Winter (2005) como características persistentes das organizações econômicas, que determinam seu comportamento ao longo do tempo.

Considerando as rotinas como hereditárias, uma nova organização econômica seria construída com base no conhecimento acumulado de outras organizações preexistentes no mesmo ramo de atividade. Dessa forma, o surgimento das inovações estaria condicionado à transformação de rotinas existentes, desencadeada pela busca por novas rotinas. Essas últimas, por sua vez, seriam selecionadas pelo mercado, tendo em vista que, para os evolucionários, o mercado age como ambiente de seleção, no qual a concorrência define quem permanece ou é excluído da atividade (Gazolla, 2012).

Para além do mercado, Nelson \& Winter (2005) salientam que as inovações surgem por influência de distintos fatores, como a pesquisa e o desenvolvimento, desencadeados pela organização econômica, o contexto em que a organização está inserida, o papel da ciência na geração de novos conhecimentos, a busca de novos hábitos frente à necessidade das

\footnotetext{
${ }^{4}$ De acordo com Marx, a força de trabalho de um indivíduo possui o mesmo valor que o tempo necessário para que ele produza o suficiente para receber o seu salário e garantir a subsistência da sua família. Na maioria das vezes, o valor desse tempo é menor do que a quantidade de força implicada para a realização do trabalho. A diferença entre esses dois valores é a mais-valia apropriada pelos capitalistas (Loyola, 2009).
} 
organizações, as combinações inesperadas entre as práxis existentes, o tamanho do mercado para o qual será comercializada a nova tecnologia, dentre outros.

Ainda que essa vertente da economia evolucionária, assim como outras ditas neoschumpeterianas ${ }^{5}$, aborde o alcance limitado dos modelos orientados por funções de produção, Marques (2009) aponta elementos que subestimam a complexidade das modificações tecnológicas, especificamente na agricultura moderna. Essa agricultura está constituída por um sistema de produção que se encontra imerso em novos contextos de acirramento de disparidades internas, de aprofundamento da globalização e agravamento dos problemas socioambientais.

Dessa maneira, a noção de produção de novidades busca evidenciar a complexidade dos distintos estilos de agricultura e se opõe à ideia de inovação conectada a fatores como a estandardização, externalização e globalização de práticas e artefatos. As novidades realizam "quebras" e "desclassificações" em relação à lógica hegemônica da sociedade e do contexto institucional (Wiskerke \& Van der Ploeg, 2004; Oostindie \& Broekhuizen, 2008). Já as inovações, em especial as tecnológicas de largo alcance, buscam a substituição de fatores de produção limitantes por artefatos manufaturados pela indústria e se adequam a determinados interesses que visam induzir mudanças institucionais, cujo cerne é a acumulação capitalista (Ventura \& Milone, 2004).

O diferencial das novidades pode ser verificado a partir de três pontos centrais: i) o conhecimento utilizado para a sua construção é contextualizado; ii) as práticas envolvidas nessa construção são internalizadas ou endógenas; e iii) os processos e artefatos criados são territorializados (Oostindie \& Broekhuizen, 2008). A primeira peculiaridade está atrelada ao fato de que o conhecimento mobilizado pelos atores sociais na produção das novidades se constrói de maneira correlacionada ao contexto socioeconômico, ambiental, cultural e institucional em que os atores estão inseridos. Após a interação entre os vários tipos e fontes do conhecimento tácito e científico, o novo conhecimento está enraizado nas práticas e epistemologias desses atores sociais (Stuiver, 2008).

A emergência de novidades também está vinculada à internalização, que representa sua segunda característica central. Esse processo se relaciona com a rentabilidade e sustentabilidade das novidades, pois envolve a redução de uso de recursos externos do local e da unidade produtiva e, por conseguinte, a utilização ótima dos recursos internos (Oostindie \& Broekhuizen, 2008; Stuiver, 2008). Além disso, as novidades nascem em determinado sítio social e espacial, sendo resultantes de um conjunto de relações sociais locais e de construções realizadas por meio de redes de atores sociais.

Disso resulta que a terceira característica das novidades é a sua territorialização, dependente do tempo, dos ecossistemas e dos repertórios culturais aos quais os processos de trabalho estão associados (Wiskerke \& Van der Ploeg, 2004). Nesse sentido, o território é aqui compreendido para além de um espaço delimitado por peculiaridades ou atividades produtivas semelhantes com fronteiras geográficas estabelecidas, como resultado das ações de atores sociais em busca da resolução de problemas compartilhados (Pecqueur, 2005).

Esse conjunto de características leva à constatação de que o caráter radical das novidades se evidencia na possibilidade de romper com padrões produtivistas e puramente econômicos, os quais desconectam a sociedade da natureza e desvalorizam a identidade cultural dos atores sociais. Logo, as novidades incitam processos de transformação que partem do nível local, podendo influenciar também instâncias políticas e socioeconômicas de um nível macro.

Esses processos de transformação gerados pelas novidades estão embasados na capacidade de agência dos atores sociais, ou seja, em sua habilidade de traçar caminhos alternativos para o enfrentamento das situações problema que estão sob diversificadas formas de coerção (Long \& Van der Ploeg, 1994). Essa habilidade, alicerce da novidade, é

\footnotetext{
${ }^{5}$ As correntes neoschumpeterianas partem da premissa defendida por Schumpeter (1985) de que a mudança tecnológica é o motor do desenvolvimento capitalista, sendo a firma o locus de atuação do empresário inovador e do desenvolvimento das inovações. Os autores vinculados a essas correntes analisam as formas que as inovações são geradas e difundidas no capitalismo e defendem que o progresso técnico resulta do desenvolvimento de inovações que dependem não apenas da natureza do setor em que as inovações são geradas, mas também de fatores institucionais (Vieira, 2010).
} 
imprescindível na reconexão da sociedade com a natureza por meio do desenvolvimento da agricultura e do fomento à coprodução, formas de interação e transformação recíproca do social e do natural. Na coprodução, a utilização dos recursos naturais disponíveis localmente permite recriá-los, o que ocorre via articulação dialética com a reconstrução e fortalecimento das identidades socioculturais dos atores envolvidos em um sistema cíclico que integra os recursos naturais (Oostindie \& Broekhuizen, 2008). As reconexões impulsionadas pelas novidades possibilitam a construção de novos projetos de desenvolvimento, cujos alicerces têm dimensões da tecnologia que privilegiam aspectos socioeconômicos, culturais e ambientais dos territórios onde são geradas. Nas zonas rurais, como afirmam Van der Ploeg et al. (2004), as novidades atuam como "sementes da transição" para um novo paradigma de desenvolvimento rural.

\section{Uma novidade organizacional no litoral norte do Rio Grande do Sul}

O litoral norte do estado do Rio Grande do Sul é composto por 21 municípios, os quais totalizam uma área de $7.115,8 \mathrm{~km}^{2}$ e população de 323.112 habitantes, o que resulta numa densidade demográfica de 45,4 hab./ $\mathrm{km}^{2}$. Desse total de municípios, 14 têm população inferior a 15 mil habitantes e apenas seis apresentam demografia acima desse montante. Em relação à população total, $83 \%$ residem nos espaços considerados urbanos e $17 \%$ nas zonas rurais, situação muito próxima da encontrada no país, no qual $84 \%$ são os residentes nas áreas urbanas e 16\% nas áreas rurais (Instituto Brasileiro de Geografia e Estatística, 2010). A população atual é resultante, inicialmente, do povoamento indígena, da colonização açoriana, portuguesa e africana ocorridas no século XVIII e, posteriormente, no século XIX, das colonizações alemã, italiana, polonesa e japonesa (Cotrim et al., 2007).

As produções agropecuárias mais expressivas são arroz irrigado, banana, olerícolas, pecuária e pesca. Em relação à comercialização desses produtos, em especial das frutas e hortaliças, as oportunidades de acesso a mercados se concentram nos municípios litorâneos, que apresentam um expressivo fluxo de turistas no verão, em especial Torres e Capão da Canoa, além da região metropolitana de Porto Alegre, capital do estado, onde está situada a Central de Abastecimento do Rio Grande do Sul (Ceasa).

Nos municípios litorâneos, as entregas de produtos dos agricultores nos estabelecimentos comerciais localizados à beira de estradas que levam às praias e mesmo as vendas em domicílio são relevantes. Entretanto, a comercialização para a Ceasa é a mais significativa, devido à alta quantidade de produtos demandados em fluxo contínuo. Para a maioria dos agricultores familiares, a comercialização na Ceasa depende de agentes atravessadores que transportam a produção até os pontos de comercialização. Já o comércio nos municípios litorâneos fica restrito à época de veraneio, período em que os turistas aumentam o consumo local.

Frente a esse cenário, em setembro de 2006, um coletivo de 27 agricultores familiares de três municípios da região constituiu a Cooperativa Mista de Agricultores Familiares de Itati, Terra de Areia e Três Forquilhas (Coomafitt). Essa organização surgiu com o propósito de facilitar o acesso a diferentes mercados de produtos das unidades agrícolas familiares, além de criar novos espaços de troca de informações. Com apoio de extensionistas rurais de escritórios municipais vinculados ao serviço público da Emater/Ascar - RS, essa cooperativa vem se fortalecendo e se expandindo.

A troca de informações técnico-administrativas e a construção de laços de confiança entre os agricultores e os mediadores sociais fizeram com que os representantes da Coomafitt se articulassem com outras organizações da agricultura familiar. Desse modo, essa Cooperativa estabeleceu vínculos com a Cooperativa de Consumo e Comercialização dos Pequenos Produtores Rurais do Litoral Norte (Coopviva). Sediada em Osório, a Coopviva também é constituída por agricultores familiares e conta com a assessoria de extensionistas rurais da Emater/Ascar - RS.

A articulação entre as duas cooperativas partiu do interesse em viabilizar a entrega compartilhada de produtos por meio dos Programa de Aquisição de Alimentos (PAA) e Programa Nacional de Alimentação Escolar (PNAE). Pelo PAA, os alimentos adquiridos são destinados às pessoas em situação de insegurança alimentar e nutricional (Brasil, 2015). 
Já pelo PNAE, os alimentos fornecidos pelos agricultores familiares são destinados à merenda escolar de alunos de escolas públicas de educação básica (Fundo Nacional de Desenvolvimento da Educação, 2011). Esses canais de comercialização, de forma mais significativa o PNAE, se constituíram nos mercados mais importantes da produção das famílias cooperadas. Na atualidade, os 208 agricultores associados à Coomafitt atendem via PAA a demanda de um grupo hospitalar de Porto Alegre, do restaurante universitário da Universidade Federal de Santa Maria e de mais três prefeituras municipais do litoral norte. Já pelo PNAE, esses agricultores entregam alimentos para escolas públicas de quinze municípios. A Coopviva, por sua vez, está composta por 53 associados e fornece produtos via PAA e PNAE aos municípios de São Leopoldo e Porto Alegre e para a alimentação escolar de nove outros municípios. Segundo levantamentos realizados pelos setores administrativos de ambas cooperativas, as ações conjuntas beneficiam mais de 65 mil pessoas pelo PAA e em torno de 350 mil pelo PNAE.

A abrangência dessas iniciativas se explica, em grande parte, pela mediação de atores que atuam como facilitadores de processos de construção de desenvolvimento rural. Essa mediação é realizada de forma mais regular e intensa pela Emater/Ascar-RS e pelas ONG Ação Nascente Maquiné (Anama) e o Centro Ecológico. O protagonismo da sociedade civil no litoral norte do Rio Grande do Sul representa um elemento diferenciador na forma de implementar as políticas públicas de compras de alimentos. Na região do Vale do Taquari, por exemplo, as gestões municipais foram as principais protagonistas do processo (Agostini \& Bourscheidt, 2018).

Os resultados favoráveis dessas articulações explicitam a internalização de práticas e da contextualização de conhecimentos. Eles permitem que as incertezas de natureza técnico-ecológicas ligadas à mudança de sistema de produção do convencional para o ecológico sejam minimizadas. Com foco na problemática ambiental, na valorização do conhecimento local e na melhoria da renda dos agricultores familiares, uma nova concepção de tecnologia passou a ser delineada na região. Tal concepção de tecnologia está fundamentada em interrelações diretas entre a prática da agricultura e a conservação ambiental e se materializa na utilização de diversas técnicas produtivas: o sombreamento dos cultivos; a rotação de espécies plantadas para não esgotar os nutrientes do solo; o uso de compostos orgânicos e biofertilizantes ${ }^{6}$ para fertilizar o solo; o uso de plantas companheiras ${ }^{7}$ para otimizar as áreas de cultivo e a qualidade das plantas; e a implantação de sistemas agroflorestais, que combinam espécies arbóreas, frutíferas e madeireiras, com cultivos agrícolas e/ou criação de animais.

Os espaços de reuniões, palestras e seminários sobre educação ambiental em escolas, feiras e eventos regionais propiciam um ambiente promissor de trocas de conhecimentos sobre as técnicas utilizadas. Com base em um constante melhoramento no uso de recursos sociais e naturais e em uma "sintonia fina" entre os fatores de crescimento nos cultivos agrícolas ${ }^{8}$, as experimentações dos agricultores são constantemente repensadas de maneira a considerar distintos fatores, como a fertilidade do solo, crescimento de espécies cultivadas e a manutenção da fauna local. Essas interrelações de agência social têm irradiado consequências para além da região de estudo, envolvendo, inclusive, consumidores da capital do estado. A ideia e a prática de uma nova relação da sociedade com a tecnologia por meio do reforço da agricultura de base ecológica têm forte correlação com a compreensão dos consumidores acerca dos processos de produção de alimentos. Por meio do chamado

${ }^{6} \mathrm{O}$ biofertilizante é um subproduto gerado pelo processo de biodigestão de compostos orgânicos que, em geral, possuem alta concentração de nitrogênio e baixa concentração de carbono. O uso dos biofertilizantes auxilia na manutenção do equilíbrio nutricional das plantas, atribuindo-lhes maior defesa frente a pragas e moléstias, sem desestruturação do solo, como ocorre com o uso de fertilizantes solúveis.

${ }^{7}$ As plantas companheiras são cultivadas de forma conjunta, pois propiciam benefícios mútuos, estimulando seu crescimento e melhorando a qualidade do solo. Esse "companheirismo" ocorre de diversas maneiras, como o sombreamento das espécies e a troca e liberação de nutrientes e compostos químicos, a exemplo de hormônios estimulantes e repelentes.

${ }^{8} \mathrm{~A}$ noção de fator de crescimento na agricultura compreende o conjunto de características determinantes de limitações e potencialidades de processos de produção agrícola. São exemplos a inclusão de nutrientes na composição do solo, a capacidade de absorção desses nutrientes pelas raízes das plantas e a disponibilidade de água no solo ao longo do tempo (Oostindie \& Broekhuizen, 2008). 
mercado institucional (PAA e PNAE), esses consumidores passaram a se aproximar dos agricultores, fortalecendo os elos das cadeias curtas de comercialização de alimentos. Esses arranjos entre distintos atores sociais, compreendidos aqui como uma novidade em consolidação, têm ampliado processos de aprendizagem coletiva, seja porque a dinamização de vínculos aumenta as possibilidades de trocas de um conhecimento contextualizado, seja porque essa dinamização rompe o isolamento de muitas iniciativas semelhantes que se encontram em andamento.

Com isso, uma nova dinâmica de desenvolvimento territorial está em curso, tendo como elemento de base a desconstrução do "convencional", na medida em que questiona os limites do modelo hegemônico de desenvolvimento e propõe a construção de uma forma mais territorializada de desenvolvimento (Cazella et al., 2009). Enquanto dinâmica territorial, sua consolidação depende do maior ou menor sucesso das alianças e mediações de conflitos da parte dos atores implicados, das disputas por recursos, do apoio político, do acesso a políticas públicas e, neste caso, da capacidade de produzir e ampliar o consumo de alimentos ecológicos. Para tanto, a articulação da produção agrícola com a otimização do uso de recursos naturais e com a ampliação das relações sociais e da capacidade organizativa representa o lócus principal da construção dessa nova dinâmica. Dessa maneira, evidenciase que as mudanças sociais e técnicas em curso englobam não somente modificações nos padrões de produção, mas também nas formas com que os agricultores reagem, se adaptam e reconstroem suas próprias relações com a natureza e com os consumidores.

\section{Os limites da participação social nas novas arenas sociais}

A emergência de novidades resulta de um processo de influência social desenvolvido por um grupo de indivíduos que se esforça na introdução ou criação de ideias novas, de novos comportamentos e modos de pensar (Van der Ploeg et al., 2004). Para sua constituição, atores sociais distintos confrontam-se, mobilizam as relações sociais e utilizam discursos com a finalidade de alcançar objetivos traçados, ou seja, constituem arenas sociais específicas. Envolver-se em tais construções inovadoras demanda, para além de certas condições dotadas por apenas alguns indivíduos, objetivos congruentes aos de outros atores sociais (Doms \& Moscovici, 1984; Long \& Van der Ploeg, 1994).

No recorte empírico em questão, a não participação de determinados indivíduos de grupos sociais específicos nas redes organizacionais se deve a distintos fatores, que compreendem desde distinções de valores culturais até diferenças significativas de renda monetária. As entrevistas realizadas com os agricultores e mediadores locais envolvidos nessas iniciativas destacam em primeiro plano a questão cultural, o individualismo e experiências anteriores de cooperação que não lograram êxito como sendo os principais motivos do ato de não participar.

A associação intrínseca do individualismo à cultura é realizada por quase a totalidade dos entrevistados envolvidos nas organizações. Quando indagados sobre o sentido que atribuem a tal correlação, esses atores sociais evidenciam o conjunto de conhecimentos e costumes, os quais são reforçados não somente por um sistema econômico capitalista, que induz a maior parte das decisões a serem tomadas de forma individual, mas igualmente as origens étnicas das populações que habitam no litoral norte do Rio Grande do Sul. Nas entrevistas com agricultores, algumas etnias presentes na composição do território, em especial a polonesa, são apontadas como portadoras de condutas de trabalho restritas ao núcleo familiar em detrimento de ações comunitárias. Enquanto outros grupos sociais, como os indígenas e quilombolas, possuem domínios sociais e especificamente formas de trabalhar com a agricultura, totalmente distintos dos deles. Tais formas compreendem desde o envolvimento da comunidade em mutirões até as trocas de dias de serviço entre os agricultores. Assim, na visão dos entrevistados, os mais aptos a cooperar seriam os agricultores provenientes das etnias portuguesa, italiana e alemã.

O fato de algumas famílias do litoral norte terem conhecimento ou vivenciado situações passadas de insucesso no empreendimento de cooperativas e associações é um agravante para a insegurança de investimento de tempo e, sobretudo, de capital financeiro nas atuais iniciativas cooperadas. A preferência pelo trabalho restrito ao universo familiar, concebido 
pela maioria dos entrevistados como "trabalho individual", foi apresentada como justificativa por cinco agricultores dentre os 26 entrevistados que não fazem parte das novas redes organizacionais. A existência de comprador fixo e a garantia de uma renda certa, sem necessidade de se envolver em um trabalho que demanda participar de reuniões e a adoção de mudanças produtivas foram as principais justificativas dos agricultores que não participam das cooperativas.

Se, de um lado, os fatores indicados pelos entrevistados envolvidos com a novidade em questão são colocados como motivos da não inclusão de novos atores sociais nas arenas configuradas na região, por outro lado, as respostas de agricultores que não fazem parte da novidade organizacional apontam motivos distintos acerca de seu distanciamento dessas arenas. Esses agricultores salientam que sua inserção na novidade organizacional é dificultada devido a um conjunto de privações vivenciadas. Ainda que essas privações não tenham sido citadas como possíveis limitações da participação social por quase nenhum dos entrevistados envolvidos nas redes, para os agricultores quilombolas, elas aparecem como imponente obstáculo, conforme salienta a entrevista a seguir:

Meu pai nunca tentou entrar numa cooperativa, nem nada do tipo, mas é muito mais por falta de dinheiro mesmo. [...]. Se não tiver dinheiro, não tem como. Vai precisar de dinheiro para arrendar uma terra, vai precisar de dinheiro para comprar as sementes e as mudas pra começar a plantar um pouco mais para vender (Agricultora quilombola, Terra de Areia/RS, mar./2016).

Segundo o administrador da Coomafitt, a média do rendimento bruto mensal de cada um dos agricultores associados à cooperativa é de $\mathrm{R} \$ 1.800,00$, o que corresponde a um valor bem acima da renda mensal per capita do litoral norte do Rio Grande do Sul, que é de $\mathrm{R} \$ 801,13$ (Brasil, 2015). Ademais, vale destacar que essa região apresenta uma média de $43,5 \%$ de indivíduos em situação de pobreza ${ }^{9}$, ou seja, indivíduos que não conseguem suprir suas necessidades básicas e, tampouco, vincularem-se a um dispositivo coletivo, como a Coomafitt (Brasil, 2015). Segundo um mediador social de uma das ONG com atuação na zona de estudo, a privação de renda faz com certos agricultores não possam e, em alguns casos, não queiram se envolver em organizações sociais que, naquele momento, são por eles associadas mais a incertezas do que a garantias de melhorias da sua condição de reprodução social.

O encadeamento de privações de liberdades, que variam desde o acesso à terra, alimentação, saneamento, água potável, educação até à política e direitos cívicos, acaba por resultar na não participação desses indivíduos em decisões importantes da vida pública (Sen, 2000). A privação de liberdades está relacionada à idade, sexo, raça, papel social, local de nascimento e outras variáveis sobre as quais o indivíduo não tem controle. A privação de renda, por exemplo, está diretamente correlacionada à privação de informação e de educação (Sen, 2000).

Na região de estudo fica evidente que certas liberdades têm uma função instrumental na promoção de outras formas de liberdade. As liberdades econômica e política retroalimentam-se e a dificuldade de acesso à educação pelas populações pobres implica em sua continuidade à margem dos processos de desenvolvimento rural. A privação dos capitais cultural e econômico entrava a participação desse público na edificação da novidade organizacional, como ocorre com a família dessa agricultora em situação de vulnerabilidade socioeconômica:

Eu nunca fui buscar um grupo nem nada, porque eu não tinha um suporte financeiro que me ajudasse a ir além. [...]. O problema também é que eu até sei ler um pouco, mas meu marido é analfabeto, então ele não tem como participar dessas coisas. A gente até teria vontade, mas assim fica bem difícil [...]. (Agricultor, Itati/RS, jan/2016).

\footnotetext{
Indivíduos com renda domiciliar per capita igual ou inferior a $\mathrm{R} \$ 255,00$ mensais, valor equivalente a $1 / 2$ salário mínimo em agosto de 2010. O universo de indivíduos é limitado àqueles que vivem em domicílios particulares e forma permanente (Brasil, 2015).
} 
Para Foucault (2003), todo sistema de educação é uma maneira política de manter ou modificar a apropriação dos discursos, com os saberes e os poderes que eles trazem consigo, inclusive de transformação da realidade social. No litoral norte do Rio Grande do Sul, o não acesso a esse sistema e, mais fortemente, o não encaixe das construções culturais no padrão hegemônico, implicam em uma dificuldade de melhoria de qualidade de vida. As expressões abaixo, de uma agricultora vinculada à comunidade quilombola Morro do Chapéu, localizada no município de Três Forquilhas, e de um indígena da Terra Indígena Barra do Ouro, do município de Maquiné, são representativas da distinção de visões de mundo entre esses públicos e os demais agricultores familiares, bem como das barreiras que são edificadas:

A gente é excluído até hoje. [...]. E só agora é que o povo está se acordando, vendo que tem que estudar igual aos brancos [...]. Mas o nosso povo tem mais dificuldade quando é para sair para estudar. Se tem 100 alunos, só $10 \%$ é de negro, os outros $90 \%$ é branco (Agricultora quilombola, Três Forquilhas/RS, jan/2016).

Trabalhar com o branco foi muito diferente do que a gente tava acostumado a fazer. Mas tem que se virar, né? [...] O branco usa coisas na terra que o Guarani não usa. Por isso também que eu saí. Uma vez, eu trabalhava assim colocando o veneno na verdura, em mês de janeiro ainda, isso quase me matou. Parecia que eu tava enforcado, por três dias eu não falava. Fechou tudo a minha garganta. Eu não usava máscara, nada. [...]. No começo eu não conhecia nada, eu pensei que era fácil. Agora eu não quero mais trabalhar com o branco. Melhor ficar assim, na aldeia. Mas eu queria melhorar assim na aldeia, do nosso jeito, mas não é fácil (Agricultor indígena, Maquiné/RS, mar/2016).

As arenas sociais constituídas por um coletivo de agências e balizadas por uma distribuição de domínios sociais, ou seja, por regulamentações que definem direitos e deveres, se consolidam como importantes instrumentos de resistência e permanência de um grupo social que busca a construção de formas alternativas de desenvolvimento rural. Todavia, o envolvimento nessas arenas é circunscrito a indivíduos que se encontram em uma situação semelhante e compartilham das mesmas condições culturais, socioeconômicas e políticas (Ferreira et al., 2007). A projeção da própria identidade de um indivíduo a um grupo de pertencimento está diretamente atrelada ao seu comprometimento e envolvimento emocional nesse coletivo. A imagem que o indivíduo constrói de si mesmo encontra-se também conectada àquela que ele tem de seu grupo, o que leva à defesa dos valores do conjunto. Entretanto, a proteção dos seus interesses e, por consequência, dos interesses do grupo, incita a diferenciação social (Jodelet, 1996).

De acordo com Bourdieu (1979), é preciso dispor de capital cultural no estado incorporado para que a participação social se efetive. A incorporação desse tipo de capital pressupõe um trabalho de assimilação, que exige investimentos de longa duração para se tornar parte integrante do indivíduo. Assim, apesar do acesso ao capital econômico ser significativo na construção de agência, sua privação não se trata do único fator de limitação à participação social. A acumulação de capital cultural pelos indivíduos permite a construção de capital social, ou seja, o envolvimento dos indivíduos nas redes de relações sociais, o que possibilita aceder a recursos de membros do grupo ou de uma rede de atores. Esse capital está relacionado à apropriação da linguagem e dos conhecimentos considerados legítimos pela sociedade hegemônica (Bourdieu, 1979; Sen, 2000).

O capital social se constitui como uma combinação de recursos já existentes, ou potenciais, que possuem vínculo estreito com uma rede de interreconhecimento. As relações estabelecidas entre os atores pertencentes a um grupo não advêm apenas de trocas materiais, mas, sobretudo, de trocas simbólicas, cuja instauração e perpetuação supõem o reconhecimento dessa proximidade. São essas redes sociais que dão ao indivíduo o sentimento de pertencimento a uma coletividade e, ao mesmo tempo, a sua construção como agente social. Contudo, uma vez que há uma tendência na aceitação somente daqueles que são culturalmente semelhantes e no distanciamento, ou rejeição, daqueles que são diferentes, esse processo leva à exclusão de determinados indivíduos na constituição das redes sociais (Bourdieu, 1979). 
A exclusão social corresponde justamente a um sentimento de incompatibilidade entre os interesses e formas de atuação de um coletivo e o medo de um desprovimento de posições e privilégios do grupo ao qual se pertence. Trata-se do resultado da articulação de processos socioeconômicos e políticos e do cerceamento de grupos sociais que não fazem parte da cultura considerada hegemônica (Jodelet, 1996). Os processos históricos de exclusão sociocultural, política e econômica de públicos específicos, como os indígenas e quilombolas no Brasil, contribuem para asseverar as barreiras de efetiva participação desses públicos nas estratégias que estão sendo postas em marcha na região de estudo, majoritariamente, por agricultores descendentes de portugueses, italianos e alemães.

No litoral norte do Rio Grande do Sul, uma das barreiras à melhoria de condições sociais dos indígenas e quilombolas decorre do fato de as organizações atuantes na produção da novidade sociotécnica aqui analisada muitas vezes não compreenderem as lógicas de vida desses povos tradicionais ou até mesmo não apoiarem suas iniciativas. O legado da "modernização" da agricultura explica, em grande medida, que o cotidiano dos profissionais que atuam no espaço rural seja orientado aos agricultores que já se encontram consolidados do ponto de vista socioeconômico ou para aqueles que reúnem capitais cultural e social que permitam alcançar situação semelhante. Trata-se da reprodução de práticas convencionais promovidas pelos serviços públicos de extensão rural que se direcionam a agricultores que mais facilmente acolhem suas propostas técnicas (Caporal, 1991). Assim, ainda que os objetivos da Emater/Ascar e das ONG locais convirjam para abranger a diversidade de públicos existente no litoral norte do Rio Grande do Sul, persiste uma forte tendência de suas ações favorecerem agricultores melhor situados na hierarquia social.

Diversas análises sobre as recentes políticas públicas brasileiras constituídas com o intuito de estimular processos diferenciados de desenvolvimento rural favorecem grupos sociais que detêm as melhores condições socioeconômicas (Capellesso \& Cazella, 2013; Capellesso et al., 2018; Tecchio, 2012, 2017; Aquino et al., 2018). No caso específico de ações de desenvolvimento rural que se desviam no modelo hegemônico de agricultura, percebe-se uma concentração em torno dos de "três agros" - agroecologia, agroturismo e agroindústria familiar - implementada por organizações governamentais, ONG e movimentos sociais e sindicais, os quais não têm entre seu público prioritário de trabalho as populações pobres (Cazella, 2006).

A compreensão de certos agricultores envolvidos na novidade organizacional acerca da não participação de outros agricultores, em especial daqueles em situação de pobreza, desconsidera a presença de condicionantes que há por detrás da participação nessas redes sociais tecidas. A argumentação de que esses sujeitos se "acomodam naquela situação" acaba sendo o discurso mais reproduzido pelos agricultores consolidados ou em processo de consolidação socioeconômica. De acordo com Moura Junior \& Ximenes (2016), a identidade social estigmatizada das pessoas pobres se estrutura em pressupostos e formas cristalizadas de reconhecimento do indivíduo, as quais enfraquecem as possibilidades de mudança, tanto do indivíduo reconhecido por esse prisma identitário estigmatizado quanto da própria construção de sua identidade. A estigmatização faz com que os pobres acabem por expressar um tipo de discurso a favor de uma autodeterminação excludente, colocando-se diante do outro de forma depreciativa.

A pessoa em situação de pobreza pode sentir-se humilhada por conta de sua condição socioeconômica, o que enfraquece sua habilidade de enfrentamento de tal situação. O sentimento pode ser ainda mais grave quando essa pessoa se depara com um ambiente no qual seus valores culturais destoam daqueles considerados comuns, como revela o trecho abaixo de entrevista realizada com uma agricultora quilombola:

Aqueles que têm menos dinheiro, menos cultura ou inteligência [sic], não sei como chamar isso, eles mesmos se excluem, têm medo de chegar. [...]. Minha própria gente, minha família, eles se colocam prá baixo [silêncio]. Nem chegam nesses espaços de cooperativa nem nada (Agricultora quilombola, Três Forquilhas/RS, jan./2016).

Apesar dos atores sociais envolvidos com a emergência e consolidação da novidade organizacional reconhecerem as limitações do processo participativo, as possíveis soluções 
que se apresentam ao enfrentamento dessa situação esbarram na existência de uma série de fatores. A ausência de recursos econômicos e sociais disponíveis para empreender ações que prevejam a transformação desse cenário quase sempre aparece como a principal justificativa. Soma-se a isso a falta de tradição das principais organizações profissionais que atuam com o tema do desenvolvimento rural na região Sul em promover ações junto às comunidades tradicionais. A compreensão das limitações desses processos de construção de novidades, particularmente no tocante à exclusão social, baseia-se na análise da participação não somente por meio das relações internas e na diversidade que sustentam tais iniciativas, mas também pelas relações que essa participação mantém com a multiplicidade de dimensões e atores que compõem o cenário na qual ela se desenvolve.

\section{5. À guisa de conclusão}

Críticos a processos de "modernização" tecnológica homogeneizantes causadores de inúmeras consequências socioambientais negativas no meio rural, distintos atores sociais do recorte empírico analisado reagiram de forma criativa e coletiva frente aos desafios impostos por esse processo, seguindo na contramão do modelo dito modernizante.

Em meio ao resgate de técnicas tradicionais mescladas a novas práticas, identificaram-se como novidade na região de estudo ações de cooperação, que mobilizaram diferentes interesses e conhecimentos de distintas organizações. Essa novidade se assenta na busca constante pelo equilíbrio entre os fatores que limitam a produção dos agricultores familiares, em iniciativas vinculadas à preservação dos recursos naturais e às novas perspectivas de trabalho na agricultura. Essas novas perspectivas, por sua vez, são indutoras de atividades diferenciadas, a exemplo das agroindústrias familiares, da comercialização dos alimentos em novos circuitos curtos e, ainda, da interrelação com novos atores sociais, sejam esses agricultores, mediadores sociais, pesquisadores e consumidores.

Fortalecida por políticas públicas voltadas à agricultura familiar, em especial as vinculadas a compras públicas de alimentos, essa novidade desencadeou novas práticas agrícolas e organizacionais territorializadas. Embora esse processo desviante, ainda em construção, esteja propiciando mudanças tecnológicas significativas na região, sua abrangência se apresenta limitada no que se refere à inclusão de diferentes tipos de agricultores familiares.

Evidenciou-se que os agricultores envolvidos nessa novidade são os que acessam as políticas públicas de caráter produtivo, a exemplo do crédito rural e dos programas de compras públicas de alimentos, e mais se beneficiam do suporte sociotécnico da Emater e de ONG locais. Relevou-se que a participação restrita a esse segmento de agricultores se dá devido a uma série de fatores. A incongruência entre os projetos individuais e o projeto coletivo de desenvolvimento é um deles. Alguns entrevistados afirmam que a manutenção de um sistema produtivo convencional e a comercialização de seus produtos para um único comprador se apresentam a eles como uma melhor opção do que sua inserção em uma organização cooperativa.

Entretanto, as razões mais ostensivas para a não participação da maior parte dos agricultores familiares decorre da não apropriação de capitais específicos, como o cultural, o social e o econômico, e a diferença significativa de lógicas de trabalho na agricultura. A inviabilização dessa participação acaba sendo maior entre indígenas e quilombolas, cuja privação desses capitais é ainda mais expressiva quando comparados aos demais agricultores pobres da região.

Grande parte dos agricultores em vulnerabilidade socioeconômica, que mais necessitam ser favorecidos por políticas públicas, sociais e produtivas, não possui sequer acesso facilitado a informações sobre essas políticas, nem recebe serviços qualificados de assistência técnica e extensão rural. Muitas vezes, esses agricultores estão vinculados a sindicatos inoperantes dos trabalhadores rurais e não integram as redes sociais de ONG atuantes na região, o que resulta em sua marginalização dos processos organizativos que se constroem no litoral norte.

As reflexões acerca das condicionantes para o envolvimento de distintos atores sociais nessas disputas de interesses realçam o fato de que o distanciamento dos agricultores empobrecidos, em especial indígenas e quilombolas, desses processos inovadores está 
relacionado a um profundo desconhecimento da diversidade de suas lógicas de reprodução social por parte dos serviços públicos de assistência técnica e extensão rural, das agências de pesquisa científica e dos próprios gestores das organizações de agricultores, que se revelam dispostos a se envolverem na transformação socioeconômica das famílias em vulnerabilidade socioeconômica. Dessa forma, com base nas análises realizadas, mais importante do que tentar integrar esses públicos às iniciativas em curso, as quais muitas vezes não condizem com seus projetos de vida, é compreender suas formas de produção e relações específicas com os recursos naturais.

\section{Referências}

Ação Nascente Maquiné - ANAMA. Universidade Federal do Rio Grande do Sul - UFRGS. Faculdade de Ciências Econômicas. Programa de Pós-graduação em Desenvolvimento Rural - PGDR. (2000). Diagnóstico socioeconômico e ambiental do município de Maquiné - RS: perspectiva para o desenvolvimento rural sustentável. Porto Alegre: UFRGS.

Agostini, C., \& Bourscheidt, H. J. (2018). A implementação do programa de aquisição de alimentos nos municípios do Vale do Taquari (RS): uma análise da percepção dos executivos municipais. Revista de Economia e Sociologia Rural, 56(2), 275-292. http://dx.doi.org/10.1590/1234-5678180694790560206

Aquino, J. R., Gazolla, M., \& Schneider, S. (2018). Dualismo no campo e desigualdades internas na agricultura familiar brasileira. Revista de Economia e Sociologia Rural, 56(1), 123-142. http://dx.doi.org/10.1590/1234-56781806-94790560108

Arce, A., \& Long, N. (2000). Reconfiguring modernity and development from an anthropological perspective. In A. Arce \& N. Long (Eds.), Anthropology, development and modernities: exploring discourses, counter-tendencies and violence (pp. 1-31). London: Routledge.

Bourdieu, P. (1979). P Les trois états du capital culturel. Actes de la Recherche en Sciences Sociales, 30(1), 3-6. http://dx.doi.org/10.3406/arss.1979.2654

Brasil. Ministério do Desenvolvimento Agrário - MDA. (2015). Perfil territorial: litoral - RS. Recuperado em 28 de abril de 2015, de http://sit.mda.govol.br/download/caderno/caderno_territorial_229_Litoral\%20-\%20RS.pdf

Capellesso, A. J., \& Cazella, A. A. (2013). Os sistemas de financiamento na pesca artesanal: um estudo de caso no litoral Centro-Sul Catarinense. Revista de Economia e Sociologia Rural, 51(2), 275-294. http://dx.doi.org/10.1590/S0103-20032013000200004

Capellesso, A. J., Cazella, A. A., \& Búrigo, F. L. (2018). Evolução do Pronaf Crédito no Período 1996-2013: redimensionando o acesso pelos cadastros de pessoa física. Revista de Economia e Sociologia Rural, 56(3), 437-450. http://dx.doi.org/10.1590/1234-56781806-94790560305

Caporal, F. R. (1991). A extensão rural e os limites à prática dos extensionistas do serviço público (Dissertação de mestrado). Departamento de Educação Agrícola e Extensão Rural, Universidade Federal de Santa Maria, Santa Maria.

Caporal, F. R., \& Costabeber, J. A. (2004). Agroecologia e extensão rural sustentável: contribuições para a promoção do desenvolvimento rural sustentável (Vol. 1). Brasília: MDA/SAF/DATER/IICA.

Carneiro, M. J. (1999). Agricultores familiares e pluriatividade: tipologias e políticas. In L. F. C. Costa, R. J. Moreira \& R. Bruno (Eds.), Mundo rural e tempo presente (pp. 323-344). Rio de Janeiro: Mauad.

Cazella, A. A. (2006). Contribuições metodológicas da sócio-antropologia para o desenvolvimento territorial sustentável. Eisforia, 4, 225-247.

Cazella, A. A., Bonnal, P., \& Maluf, R. S. (2009). Agricultura familiar: multifuncionalidade e desenvolvimento territorial no Brasil. Rio de Janeiro: Mauad X.

Cotrim, D. S., Garcez, D., \& Miguel, L. A. (2007). Litoral Norte do Rio Grande do Sul: sob a perspectiva de diferenciação e evolução dos sistemas agrários. Recuperado em 16 de maio de 2013, de <http://www.cnpat.embrapa.br/sbsp/anais/Trab_Format_PDF/51.pdf

Doms, M., \& Moscovici, S. (1984). Innovation et influence des minorités. In S. Moscovici (Ed.), Psychologie sociale (pp. 51-89). Paris: Presses Universitaires de France.

Fairclought, N. (2001). Discurso e mudança social. Brasília: Editora UnB.

Ferreira, A. D. D., Brandenburg, A., da Silva, O. H., Rodrigues, A. S., Santos, E. B., \& Pinheiro, G. (2007). Resistência e empoderamento no mundo rural. Estudos Sociedade e Agricultura, 15(1), 123-159.

Foucault, M. (2003). A ordem do discurso. São Paulo: Loyola. 
Fraser, M. T. D., \& Gondim, S. M. G. (2004). Da fala do outro ao texto negociado: discussões sobre a entrevista na pesquisa qualitativa. Paideia, 14(28), 139-152.

Fundação Estadual de Planejamento Metropolitano e Regional - METROPLAN. (2014). Recuperado em 7 de abril de 2014, de

http://www.metroplan.rs.govol.br/conteudo/1356/?Perfil_dos_munic\%C3\%ADpios_da_Regi\%C3\%A3 o_Metropolitana_de_Porto_Alegre_\%28RMPA\%29_e_Aglomerados_Urbanos

Fundo Nacional de Desenvolvimento da Educação - FNDE. (2011). Programa de Alimentação Escolar (PNAE): apresentação. Recuperado em 18 de outubro de 2011, de http://www.fnde.govol.br/programas/alimentacao-escolar/alimentacao-escolar-apresentacao

Gazolla, M. (2012). Conhecimentos, produção de novidades e ações institucionais: cadeias curtas das agroindústrias familiares (Tese de doutorado). Faculdade de Ciências Econômicas, Universidade Federal do Rio Grande do Sul, Porto Alegre.

Gerhardt, C. H. (2002). Agricultores familiares, mediadores sociais e meio ambiente: a construção da 'problemática ambiental' em agro-ecosistemas (Dissertação de mestrado). Faculdade de Ciências Econômicas, Universidade Federal do Rio Grande do Sul.

Giddens, A. (1989). A constituição da sociedade. São Paulo: Martins Fontes.

Instituto Brasileiro de Geografia e Estatística - IBGE. (2010). Censo demográfico: Brasil 2010. Rio de Janeiro. Recuperado em 10 de julho de 2013, de www.ibge.govol.br

Jodelet, D. (1996). Les processus psyco-sociaux de l'exclusion. In S. Paugam (Ed.), L'exclusion l'état des savoirs (pp. 66-77). Paris: La Découverte.

Lamarche, H. (1993). A agricultura familiar. Campinas: UNICAMP.

Long, N. (2007). Sociología del desarrollo: una perspectiva centrada en el actor. México: Centro de Investigaciones y Estudios Superiores en Antropología Social, El Colegio de San Luis.

Long, N., \& Van der Ploeg, J. (1994). Heterogeneity, actor and structure: towards a reconstitution of the concept of structure. In D. Booth (Ed.), Rethinking social development theory, research and practice (pp. 62-90). England: Longman Scientific \& Technical.

Loyola, P. R. G. (2009). Valor e mais-valia: examinando a atualidade do pensamento econômico de Marx. Revista de Filosofia Argumentos, 1(2), 130-138.

Marques, F. C. (2009). Velhos conhecimentos, novos desenvolvimentos: transições no regime sociotécnico da agricultura: a produção de novidades entre agricultores produtores de plantas medicinais no Sul do Brasil (Tese de doutorado). Faculdade de Ciências Econômicas, Universidade Federal do Rio Grande do Sul, Porto Alegre.

Marx, K. (2006). O Capital: crítica da economia política: livro 1 (R. Sant'Anna, Trad., 21. ed., Vol. 2, O processo de produção do Capital). Rio de Janeiro: Civilização Brasileira.

Medeiros, M. (2017). Sendas da sustentabilidade no desenvolvimento rural: os passos e os percalços da construção de um novo código sociotécnico em campo (Tese de doutorado). Centro de Ciências Agrárias, Universidade Federal de Santa Catarina.

Mello, M. (2009). Sementes que brotam da crise: a produção de novidades organizacionais na agricultura familiar do Oeste de Santa Catarina (Tese de doutorado). Faculdade de Ciências Econômicas, Universidade Federal do Rio Grande do Sul, Porto Alegre.

Moura Junior, J. F., \& Ximenes, V. M. (2016). A identidade social estigmatizada de pobre: uma constituição opressora. Fractal Revista de Psicología, 28(1), 76-83. http://dx.doi.org/10.1590/19840292/1051

Nelson, R. R., \& Winter, S. G. (1977). In search of useful theory of innovation. Research Policy, 6(1), 36-76. http://dx.doi.org/10.1016/0048-7333(77)90029-4

Nelson, R. R., \& Winter, S. G. (2005). Uma teoria evolucionária da mudança econômica. Campinas: Editora da UNICAMP.

Nicola, M. P. (2015). Espaço protegido e desenvolvimento rural: práticas e trajetórias na Pecuária Familiar da Região Centro Sul do Rio Grande do Sul (Tese de doutorado). Faculdade de Ciências Econômicas, Universidade Federal do Rio Grande do Sul, Porto Alegre.

Oliveira, D. (2014). Produção de conhecimentos e inovações na transição agroecológica: o caso da agricultura ecológica de Ipê e Antônio Prado/RS (Tese de doutorado). Faculdade de Ciências Econômicas, Universidade Federal do Rio Grande do Sul, Porto Alegre.

Oostindie, H., \& Broekhuizen, R. (2008). The dinamic of novelty production. In J. D. Van der Ploeg \& T. Marsden (Eds.), Unfolding webs: the dynamics of regional rural development (262 p.). Assen: Van Gorgum. 
Pecqueur, B. (2005). O desenvolvimento territorial: uma nova abordagem dos processos de desenvolvimento para as economias do Sul. Raízes, 24(1-2), 10-22.

Schumpeter, J. A. (1985). Teoria do desenvolvimento econômico: uma investigação sobre lucros, crédito, juro e o ciclo econômico (M. S. Possas, Trad.). São Paulo: Nova Cultural.

Sen, A. (2000). Desenvolvimento como liberdade (409 p.). São Paulo: Companhia das Letras.

Smith, A. (1996). A riqueza das nações: investigação sobre sua natureza e suas causas. São Paulo: Abril Cultural.

Stuiver, M. (2008). Regime, change and storylines: a sociological analysis of manure practices in contemporary Dutch farming. Netherlands: Wageningen Univol.

Tecchio, A. (2012). Políticas públicas de desenvolvimento territorial e superação da pobreza no meio rural brasileiro: estudo de caso no Território Meio Oeste Contestado (SC) (Dissertação de mestrado). Universidade Federal de Santa Catarina, Florianópolis.

Tecchio, A. (2017). Pobreza e territorialização da ação pública no Território Meio Oeste Contestado (SC) (Tese de doutorado). Universidade Federal Rural do Rio de Janeiro, Rio de Janeiro.

Van der Ploeg, J. D., Bouma, J., Rip, A., Rijkenberg, F. H. J., Ventura, F., \& Wiskerke, J. S. C. (2004). On regimes, novelties, niches and co-production. In J. D. Van der Ploeg \& J. S. C. Wiskerke (Eds.), Seeds of transition: essays on novelty production, niches and regimes in agriculture (pp. 1-30). Assen: Royal van Gorcum.

Ventura, F., \& Milone, P. (2004). Novelty as redefinition of farm boundaries. In J. D. Van der Ploeg \& J. S. C. Wiskerke (Eds.), Seeds of transition: essays on novelty production, niches and regimes in agriculture. Assen: Van Gorcum.

Vieira, R. M. (2010). Teorias da firma e inovação: um enfoque neo-schumpeteriano. In Anais do IV Encontro de Economia Catarinense (EEE). Recuperado em 12 de março de 2015, de http://www.apec.unes.net/eventos_escibelVOL.htm

Wiskerke, J. S. C., \& Van der Ploeg, J. D. (2004). Seeds of transition: essays on novelty production, niches and regimes in agriculture (pp. 1-28). Netherlands: Royal van Gorcum.

Submetido: $24 / \mathrm{Jul} . / 2018$.

Aceito: 20/Out./2019

Classificação JEL: JEL O - "Economic Development, Technological Change, and Growth", O3 - Technological Change

Research and Development; Intellectual Property Rights, O35 - Social Innovation 